\title{
Os Silogismos e as Suposiçôes Contraditórias de Raimundo Lúlio como Métodos RESOLUTIVOS DE INCONSISTÊNCIA
}

\author{
Guilherme Wyllie ${ }^{l}$
}

\begin{abstract}
RESUMO: No início do século XIV, Raimundo Lúlio, contrapondo-se aos mestres em Artes por ele identificados como averroistae, desenvolveria não menos que dois métodos resolutivos de inconsistência, a fim de refutar aquelas teses filosóficas que divergem da fé cristã. Um deles serve-se de silogismos contraditórios capazes de expressar a estrutura de um argumento ad hominem, ao passo que o outro nada mais é do que uma reductio ad impossibile elaborada com base em suposições contraditórias.
\end{abstract}

PALAVRAS-CHAVE: Silogismos contraditórios. Suposiçôes contraditórias. Métodos resolutivos de inconsistência. Raimundo Lúlio.

\section{INTRODUÇÃo}

Por volta de 1260, alguns dos mais representativos e influentes membros da Faculdade Parisiense de Artes passaram a estimular um vigoroso debate sobre os limites da investigação filosófica. Defensores de uma relativa autonomia da Filosofia, esses artistae, apoiando-se numa abordagem radicalmente aristotélica dos problemas especulativos mais relevantes da época, distinguiram-se sobretudo por assumir teses filosóficas aparentemente incompatíveis com a doutrina cristã. ${ }^{2}$ Tão interessantes quanto os argumentos usados para fundamentar tais teses, porém, são as diversas maneiras como as

\footnotetext{
${ }^{1}$ Departamento de Filosofia. Universidade Federal Fluminense. E-mail: guilhermewyllie@id.uff.br

${ }^{2}$ Para uma exposição panorâmica das principais doutrinas elaboradas por tais mestres em Artes, cf. WIPPEL, J. Medieval Reactions to the Encounter Between Faith and Reason. Milwaukee: Marquettte University Press, 1995; EBBESEN, S. The Paris arts faculty: Siger of Brabant, Boethius of Dacia, Radulphus Brito. In: MARENBON, J. (Ed.). Medieval Philosophy. Nova York: Routledge, 2003, p. 269-290; MARENBON, J. Medieval Philosophy, p. 254-266; DE BONI, L. A. A entrada de Aristóteles no Ocidente Medieval, p. 90-138.
} 
consequentes inconsistências entre proposiçóes filosóficas e artigos de fé foram avaliadas não só pelos autores em questão, mas também por seus adversários.

Síger de Brabante, por exemplo, dispunha de ao menos dois procedimentos capazes de tratar pares inconsistentes de proposições, cuja oposição poderia dar início a conflitos entre fé e razão. ${ }^{3}$ Diante de uma eventual incompatibilidade entre a conclusão filosófica, que, apoiada na definição de acidente, garantiria não haver acidentes separáveis de substâncias e a verdade revelada que atesta a existência de tais acidentes, Síger parece interpretar as integrantes do referido par inconsistente de proposiçôes não como $p$ e não- $p$, mas como possível- $p$ e possível não-p , evitando assim que uma contradição seja derivada de uma inconsistência, pois 'possível- $p$ e possível não- $p$ ' não se segue de 'possível- $p$, possível não- $p$ ' ${ }^{4}$ Em outra ocasião, ao estabelecer a oposição entre o ensinamento de fé segundo o qual cada ser humano possui uma alma intelectiva individual e a tese filosófica que rejeita a multiplicidade numérica das almas intelectivas, ${ }^{5}$ Síger acredita ser capaz de superar tal inconsistência recorrendo à especificação da ordem de prioridade epistêmica das proposiçóes envolvidas, com base na certeza das verdades reveladas e na falibilidade da razão, a fim de assegurar a escolha do artigo de fé em detrimento da conclusão filosófica. ${ }^{6}$

Aparentemente convencido de que a mera negação de uma conclusão filosófica seria inadmissível por acarretar a rejeição de ao menos um dos

\footnotetext{
${ }^{3}$ Há uma apresentação especialmente interessante da concepçấo de Síger sobre as relaçôes entre Filosofia e Teologia em PUTALLAZ, F.; IMBACH, R. Profession: Philosophe. Siger de Brabant. Paris: Les Éditions du Cerf, 1997, p. 107-21.

${ }^{4}$ SÍGER DE BRABANTE. Quaestiones super Librum de Causis, 41, 54-65: Unde sophistice quidam arguunt credentes naturali ratione ostendere et demonstrare quod causa prima possit facere quod accidens existat sine subiecto illius accidentis, propter hoc quod causa prima est causa omnium causarum mediarum accidentis inter ipsam et accidens, et ideo sola facere possit quod existat accidens, quamquam accidenti nulla existat aliarum causarum accidentis; et cum substantia sit aliqua causa accidentis, poterit facere ut sine substantia subsistat accidens. Ratio, ut manifeste apparet, deficit secundum ea quae prius dicta sunt. Ut tamen sane intelligatur, sciendum est quod primariam causam posse facere accidens existere sine subiecto illius accidentis confitemur. Hoc tamen est non propter istam rationem: est enim oratio conclusa peior seipsa non conclusa.

${ }^{5}$ Id. De anima intellectiva, p. 101-6.

${ }^{6}$ Ibid. p. 108: [...] et in tali dubio fidei adhaerendum est, quae omnem rationem humanam superat. Sobre o grau de certeza das verdades reveladas em Síger, veja também Id. Quaestiones in Metaphysicam: Rep. Vienensis, p. 360-1: Theologia quae est pars philosophiae procedit ex principiis notis via sensus, memoriae et experimenti, et ita in cognitione suorum principiorum potest cadere error, ut sic cognoscuntur sicut in hac scientia cognoscuntur. Sed theologia sacra scriptura procedit ex principiis notis per divinam revelationem. In tali autem cognitione non potest cadere error. Et ideo, quia principia ex quibus procedit scientia theologia quae est sacra scriptura sunt magis nota et certa quam principia ex quibus procedit scientia theologia quae est pars philosophiae, et cuius principia sunt magis nota, eius conclusiones sunt magis notae et certiores, et per consequens tota scientia magis certa, hinc est quod theologia sacra scriptura est certior.
} 
primeiros princípios da Filosofia, cuja evidência é naturalmente reconhecida pela razão, o autor anônimo de um comentário à Física de Aristóteles propóe, na mesma época, outra alternativa capaz de impedir que contradiçôes decorram logicamente de proposiçóes incompatíveis as quais expressem algum tipo de oposição entre a Filosofia e a Revelação Cristã. Presumindo que eventos naturais podem sofrer a interferência miraculosa de uma causa superior, ele sugere que conflitos entre conclusóes filosóficas, regularmente obtidas a partir dos princípios naturais da razão, e artigos de fé que se fundamentam em última análise no livre arbítrio de um agente supremo, não seriam genuínos, pois dependeriam de uma intervenção sobrenatural. ${ }^{7}$

No opúsculo De aeternitate mundi, Boécio de Dácia elabora uma versão ainda mais refinada da abordagem supracitada. Segundo ele, a verdade das conclusóes que constituem determinada ciência é relativa àqueles princípios por ela encerrados, e tal verdade sob certo aspecto (secundum quid) nem sempre coincide com a verdade absoluta (simpliciter). Com efeito, a Filosofia Natural, ao defender considerando apenas seus próprios princípios que o mundo não começou a existir de modo algum contradiz o ensinamento cristão que declara de maneira absoluta que o mundo começou a existir, pois nenhuma contradição advém quando, no que concerne ao mesmo sujeito, um predicado é simultaneamente negado sob certo aspecto e afirmado em sentido absoluto. ${ }^{8}$

Algumas décadas mais tarde, Raimundo Lúlio, contrapondo-se aos mestres em Artes por ele identificados como averroistae, desenvolveria não menos que dois métodos resolutivos de inconsistência, a fim de refutar aquelas teses filosóficas que divergem da fé cristã. Um deles serve-se de silogismos contraditórios capazes de expressar a estrutura de um argumento ad hominem,

\footnotetext{
${ }^{7}$ ANÔNIMO. Quaestiones super primum librum Physicorum, p. 3: Ex hoc enim quod philosophus concludit aliquid esse necessarium vel impossibile per causas inferiores investigabiles ratione, non contradicit fidei, quae ponit illa posse aliter se habere per causam supremam, cuius virtus et causalitas non potest comprehendi ab aliqua creatura. Cf., também KLIMA, G. Ancilla theologiae vs. domina philosophorum, p. 1-4.

${ }^{8}$ BOÉCIO DE DÁCIA. De aeternitate mundi, p. 58: Scimus enim quod qui dicit Socratem esse album, et qui negat Socratem esse album secundum quaedam, uterque dicit verum. Sic verum dicit christianus, dicens mundum et motum primum esse novum, et primum hominem fuisse, et hominem redire vivum et eundem numero, et rem generabilem fieri sine generatione, cum tamen hoc concedatur possibile esse per causam cuius virtus est maior, quam sit virtus causae naturalis. Verum etiam dicit naturalis qui dicit hoc non esse possibile ex causis et principiis naturalibus, nam naturalis nihil concedit vel negat nisi ex principiis et causis naturalibus, sicut etiam nibil negat vel concedit grammaticus secundum quod huiusmodi nisi ex principiis et causis grammaticalibus. Et quia naturalis solum considerans virtutes causarum naturalium dicit mundum et motum primum non esse novum ex eis, fides autem christiana considerans causam superiorem quam sit natura dicit mundum posse esse novum ex illa, ideo non contradicunt in aliquo.
} 
ao passo que o outro nada mais é do que uma reductio ad impossibile elaborada com base em suposiçóes contraditórias.

\section{Os SILOGIMOS CONTRADITÓRIOS ${ }^{9}$}

Em maio de 1308, após terminar a redação da Ars generalis ultima, obra que contém a versão definitiva de sua Arte, Lúlio dá início a um processo de recuperação, aprimoramento e elaboração de determinados métodos inovadores de argumentação. Preocupado com a crescente assimilação de uma das concepçôes defendidas por certos integrantes da Faculdade Parisiense de Teologia, segundo a qual os artigos de fé não poderiam ser provados, e indignado com a difusão cada vez maior das teses ensinadas pelos averroístas, na Faculdade de Artes, que sustentavam a independência da Filosofia em relação à Teologia, Lúlio, que até então residira em Montpellier, decide retornar a Paris, onde permanecerá de 1309 até 1311, para enfrentar tais desafios. ${ }^{10}$ Antes, porém, ele realiza ao longo de 1308 uma vigorosa preparação intelectual ${ }^{11}$ que incluiria não só uma profunda avaliaçáo crítica da teoria da demonstração vigente na época, mas também o estabelecimento de cinco novas técnicas argumentativas, a saber, (i) a falácia da contradição, (ii) a descoberta do médio, (iii) a demonstração pelo grau superlativo, (iv) os silogismos contraditórios e (v) as suposiçóes contraditórias. ${ }^{12}$

Não obstante a leitura cuidadosa dos textos redigidos por Lúlio durante a sua terceira e última visita a Paris revelar a aplicaçáo efetiva de grande parte das técnicas lógicas que ele elaborara, em 1308, seu método dos silogismos contraditórios é especialmente relevante, na medida em que envolve algumas concepçóes logicamente notáveis. Resultado do aperfeiçoamento

\footnotetext{
${ }^{9}$ A presente seçấo é uma versão inteiramente revisada, adaptada e ampliada de WYLLIE, G. Adaptive Reasoning in Ramon Llull's Liber de syllogismis contradictoriis. In: FIDORA, A.; SIERRA, C. (Org.). Ramon Llull: From Ars Magna to Artificial Intelligence. Menlo Park: AAAI Press, 2011, p. 117-123.

${ }^{10}$ Sobre a campanha antiaverroísta de Lúlio, em Paris, cf. IMBACH, R. Lulle face aux Averroïstes parisiens. In: Raymond Lulle et le Pays d'Oc. Toulouse: Édouard Privat, 1987, Cahiers de Fanjeaux 22.

${ }^{11}$ Uma boa descrição da preparação de Lúlio para sua campanha parisiense contra o averroísmo pode ser encontrada em BONNER, A. Syllogisms, Fallacies and Hypotheses: Llull's New Weapons to Combat the Parisian Averroists. In: DOMÍNGUEZ, F. et al. (Ed.) Aristotelica et lulliana. Steebrughe/ La Haia: Abbadia Sancti Petri/MNI, 1995, Instrumenta patristica XXVI.

${ }^{12}$ Para uma exposição panorâmica das principais doutrinas lógicas elaboradas por Lúlio, no período em questấo, cf. BONNER, A. The Art and Logic of Ramon Llull, p. 217-255.
} 
gradual de uma técnica baseada em argumentos de refutação, ${ }^{13}$ tal método foi originalmente proposto em maio de 1308, na Ars compendiosa Dei, um manual de teologia cristã destinado à orientação da atividade missionária. De fato, ao longo dessa extensa obra, certas partes e atributos de Deus, chamados por Lúlio de principia, são em sua maioria apreciados mediante a oposição de “[...] dois silogismos demonstrativos, primitivos, verdadeiros e necessários e dois não verdadeiros, de modo que através dos não verdadeiros, conheçamos os verdadeiros e vice-versa". ${ }^{14}$

Subitamente, no entanto, Lúlio abandona o método em questão e passa a empregar outras técnicas argumentativas de sua autoria até que, por volta de fevereiro de 1311, ele o retoma no Liber de syllogismis contradictoriis. De caráter antiaverroísta, esse opúsculo encerra uma estrutura dialógica efetivamente determinada pela narrativa de uma suposta contenda entre um discípulo de Lúlio e um averroísta. No prefácio, o discípulo de Lúlio atribui quarenta e quatro teses ao averroísta, advertindo-o de que provará a falsidade de cada uma delas. Em seguida, ele disponibiliza, na primeira das três seçôes que integram a obra, dez pares de argumentos e contra-argumentos presumidamente representativos do pensamento dos contendores, elaborando-os com base em determinadas proposiçóes tais como "O poder divino é poderosíssimo", que, por serem obtidas a partir de predicaçóes em grau superlativo ${ }^{15}$ das dignidades divinas, vale dizer, princípios constitutivos da realidade que se convertem em Deus, seriam, de acordo com o referido discípulo, "primitivas, verdadeiras e necessárias". Finalmente, cumpre ainda destacar que para cada argumento são também sugeridas várias consequências, cuja avaliaçáo posterior se revelará de fundamental importância. De modo geral, todos os argumentos mencionados seguem um padrão uniforme que pode ser evidenciado por meio do seguinte exemplo:

O poder divino é poderosíssimo. Tudo aquilo que é poder poderosíssimo pode existir e agir poderosíssimamente. Deus é poder poderosíssimo; logo, Deus pode existir e agir poderosíssimamente.

\footnotetext{
${ }^{13}$ Em princípio, um argumento de refutação é aquele em que a conclusão revela ser a negação da conclusão de outro argumento, de tal modo que, se um argumento assegura que $p$ é o caso, então o argumento de refutação correspondente atesta que não- $p$ é o caso (cf., por exemplo, BESNARD, P.; HUNTER, A. Elements of Argumentation, p. 2).

${ }^{14}$ RAIMUNDO LÚLIO. Ars compendiosa Dei, p. 87: Duobus modis intendimus in parte ista argumentari, uidelicet faciendo duos syllogismos demonstratiuos, primitiuos, ueros et necessarios, et duos non ueros, ut per non ueros cognoscamus ueros, et e conuerso.

${ }^{15}$ Sobre o método luliano das demonstraçóes pelo grau superlativo, cf. BONNER, A. The Art and Logic of Ramon Llull, p. 245-250.
} 
Em consequência disso se segue que não há nada que possa obrigar Deus a não ser aquele que existe e age poderosíssimamente e não há nada que possa esquivar-se dele com um poder finito.

Em contrário, argumenta-se que o poder divino não é poderosíssimo. Tudo aquilo que não é poder poderosíssimo não pode existir e agir poderosíssimamente. Deus não é poder poderosíssimo; logo, Deus não pode existir e agir poderosíssimamente.

Em consequência disso se segue que há em oposição a ele algum ente igual ou mais potente que pode impedi-lo e evitá-lo com um poder finito ou com um poder igual ou mais elevado. ${ }^{16}$

Convicto de que, valendo-se dos pares de argumentos de refutação, seria possível reconhecer a verdade ou a falsidade de determinadas proposiçóes sobre certos aspectos da natureza divina, “[...] pois se algo é predicado de Deus, então pode ser reduzido aos argumentos em questão", ${ }^{17}$ o discípulo de Lúlio realiza na segunda seção uma análise exaustiva das teses imputadas ao averroísta, para então refutá-las. Servindo-se delas, por sua vez, ele elabora pares inconsistentes de proposiçóes, tomando cada grupo antagônico de argumentos de refutação como fundamento das respectivas proposiçóes que integram esses pares inconsistentes. Subsequentemente, tal discípulo assume que aquelas consequências previamente associadas aos argumentos de refutação dos referidos grupos antagônicos seriam acarretadas pelas respectivas proposiçóes inconsistentes e seleciona uma delas, após descartar a outra, baseado na comprovação da falsidade das consequências correspondentes. Enfim, segue uma passagem que exemplifica como o recurso ao método em questão permite a refutação da tese averroísta que nega a infinitude da força divina:

Que Deus não é uma força infinita, os dez silogismos anteriormente citados asseguram, mas se [ele] não é uma força infinita, os dez silogismos

${ }^{16}$ RAIMUNDO LÚLIO. Liber de syllogismis contradictoriis, p. 174: Diuina potestas est potentissima. Quidquid est potestas potentissima, potest existere et agere potentissime. Deus est potestas potentissima; ergo Deus potest existere et agere potentissime. Ad consequentiam istius sequitur, quod non sit aliquid, quod possit cogere Deum, quin Deus sit existens et agens potentissime, et quod non sit aliquid, quod possit euadere ab ipso cum finito posse. In contrarium arguitur sic: Diuina potestas non est potentissima. Quidquid non est potestas potentissima, non potest existere et agere potentissime. Deus non est potestas potentissima; ergo Deus non potest existere et agere potentissime. Ad consequentiam istius sequitur, quod est aliquod ens sibi oppositum coaequatum aut magis potens, quod potest ipsum impedire, et ab ipso euadere cum finito posse, aut cum posse ei coaequato, aut cum posse altiori.

${ }^{17}$ Ibid. p. 177: Ait Raimundus: Feci niginti syllogismos oppositos, cum quibus potest homo de Deo cognoscere suum existere et agere. Et ideo, si de Deo aliquid praedicetur, ad ipsos syllogismos potest reduci, et cum ipsis cognosci, si propositio sit uera aut falsa, cum quidquid de Deo dici potest, sit in ipsis implicite aut explicite. 
posteriores contestam. Discorrido com o apoio dos mesmos silogismos, o intelecto humano reconhece, suposto que seja sutil, seguro, discreto e não perverso, que Deus é uma força infinita. Mas se julgasse em sentido oposto, seria perverso e indiscreto e isso é evidente por si.

Pretendemos, no entanto, expor isso de alguma maneira. Se o poder divino não é infinito, então há algo que o impede de ser infinito. Tal impedimento, por sua vez, é ótimo, pois tudo aquilo que existe em Deus é máximo. E é eternalíssimo, pois tudo aquilo que existe em Deus é eternalíssimo. E é poderosíssimo, pois tudo aquilo que existe em Deus é poderosíssimo. Do que necessariamente se segue que ótimo é péssimo, máximo é mínimo, etc. Mas, uma vez que tais contradições são impossíveis, demonstrou-se portanto que Deus é uma força infinita e isso é absolutamente inteligível, ao passo que seu oposto não é de modo algum crível. ${ }^{18}$

Entre as condutas acima descritas, são de particular relevância a especificação das consequências acarretadas pelos argumentos e enunciados averroístas, bem como a posterior utilização desses elementos na justificação das teses opostas àquilo que o averroísta previamente assumira, pois ambas indicam que Lúlio se serviu da estrutura a qual caracteriza a forma tradicional dos argumentos ad hominem para criar seu método dos silogismos contraditórios.

Originalmente concebido tanto nos Tópicos, quanto nas Refutaçôes Sofisticas, como um tipo de peirastikos logos, vale dizer, um argumento empregado para examinar o conhecimento de alguém com base em suas próprias concepçóes, o que ora denominamos argumentum ad hominem era, conforme Aristóteles, um silogismo cujas premissas se resumiriam ao que fora concedido por determinado contendor, e a conclusão consistiria na contraditória da tese por ele sustentada. ${ }^{19} \mathrm{Na}$ Idade Média, grande parte dos lógicos passaria, sob a

\footnotetext{
${ }^{18}$ RAIMUNDO LÚLIO. Liber de syllogismis contradictoriis, p. 178: Quod Deus sit infiniti uigoris, decem praedicti syllogismi primi hoc testantur. Et si non est infiniti nigoris, decem syllogismi posteriores contradicunt. Intellectus autem humanus, discursus per ipsos syllogismos, posito quod sit subtilis, fundatus, discretus et non peruersus cognoscit, quod Deus est infiniti uigoris; et si iudicaret in opposito, esset peruersus et indiscretus. Et hoc per se patet. Tamen aliquo modo super hoc intendimus declarare. Si dinina potestas non est infinita, aliquid est, quod impedit, quod ipsa non sit infinita. Et illud impedimentum est optimum, cum quidquid sit in Deo, sit optimum. Et est maximum, cum quidquid sit in Deo, sit maximum. Et est aeternalissimum, cum quidquid sit in Deo, sit aeternalissimum. Et est potentissimum, cum quidquid sit in Deo, sit potentissimum. Ex quo sequitur necessarie, quod optimum sit pessimum, et maximum minimum etc.. Et quia tales contradictiones sunt impossibiles, demonstratum est ergo, quod Deus est infiniti nigoris.

${ }^{19}$ Cf. ARISTÓTELES, Tópicos, I, 2, 101a25 e Refutaçóes Sofisticas, 2, 165a37. Para a história do argumentum ad hominem, cf. NUCHELMANS, G. On the Fourfold Roots of the argumentum ad
} 
influência de Boécio, a chamar tal procedimento argumentativo de disputatio temptativa. De acordo com alguns deles, porém, sua capacidade probatória revelar-se-ia limitada. Pedro Hispano, por exemplo, observa que numa disputa crítica as premissas envolvidas não seriam absolutamente prováveis, pois se restringiriam ao que fora admitido por um dos contendores. ${ }^{20}$ De modo análogo, ao comentar determinada passagem da Metafísica, onde Aristóteles distingue uma prova em sentido absoluto (haplōs apodeixis) de uma prova em relação a essa pessoa (pros tonde apodeixis), ${ }^{21}$ Tomás de Aquino recorre à expressão demonstratio ad hominem para designar uma prova do princípio segundo o qual nada pode simultaneamente ser e náo ser contra aquele que o renuncia em favor de algo menos evidente. ${ }^{22}$

Atento aos procedimentos argumentativos em vigor no final da Idade Média, Lúlio, que provavelmente conhecia a disputatio temptativa, ${ }^{23}$ projeta sua técnica dos silogismos contraditórios convencido de que a refutação das teses atribuídas ao averroísta não requer nada além do que já fora por ele assumido. $\mathrm{Na}$ realidade, o reconhecimento de que tais teses acarretam certas consequências originalmente vinculadas aos argumentos averroístas e a subsequente negação dessas consequências bastariam, segundo ele, para determinar a falsidade das teses em questão.

hominem. In: KRABE, E.C.W.; DALITZ, R.J.; SMIT, P. (Ed.). Empirical Logic and Public Debate. Amsterdam: Rodopi, 1993, p. 37-47; VAN EEMEREN, F. H.; GROOTENDORST, R. The History of the argumentum ad hominem since the Seventeenth Century. In: KRABE, E.C.W.; DALITZ, R.J.; SMIT, P. (Ed.). Empirical Logic and Public Debate. Amsterdam: Rodopi, 1993, p. 49-68; CHICHI, G. M. The Greek Roots of the ad hominem-Argument. Argumentation, 16, p. 333-348, 2002.

${ }^{20}$ PEDRO HISPANO. Tractatus, p. 91: Disputatio temptativa est ex hiis que videntur respondenti et necessarium est ei scire qui simulat se habere scientiam. Huius autem disputationis instrumentum est temptativus sillogismus. Temptativus autem sillogismus est qui est sillogizatus ex probabilibus respondenti. Unde si est aliquando ex necessariis, vel ex falsis, vel ex probabilibus simpliciter, hoc non est inquantum talia sunt, sed inquantum probabilia sunt respondenti. [...] Dialecticus autem accipit probabile simpliciter. [...] Sed temptativus non accipit tam probabile, sed solum probabile respondenti et ita probabile secundum quid.

${ }^{21}$ Cf. ARISTÓTELES. Met. XI, 5, 1062a2-3.

${ }^{22}$ TOMÁS DE AQUINO. In duodecim libros Metaphysicorum Aristotelis expositio, Lectio V, n. 2213: Et de talibus secundo dicit, quod de praedicto principio et similibus non potest esse simpliciter demonstratio, sed potest esse demonstratio ad hominem. Quod autem non possit simpliciter demonstrari, probat ex hoc, quod non contingit facere syllogismum ad hoc principium demonstrandum ex aliquo principio magis noto; quod oporteret si contingeret illud principium simpliciter demonstrare. Sed ad hominem contingit hoc principium demonstrare, qui concedit aliquid aliud, licet minus notum, et hoc negat.

${ }^{23}$ Lúlio aparentemente conhecia ao menos a breve descrição da disputatio temptativa presente no opúsculo De fallaciis, cuja autoria fora por vezes atribuída a Tomás de Aquino (Cf. TOMÁS DE AQUINO. De fallaciis, p. 403. Sobre o forte influxo da referida obra no Liber de novis fallaciis, cf. WYLLIE, G.; FIDORA. A. Ramon Llull i el tractat De fallaciis del pseudo-Tomàs d'Aquino. Enrahonar, 42, 2009, p. 11-19). 
Embora o método dos silogismos contraditórios manifeste a oposição entre as concepçóes lulianas e averroístas mediante pares inconsistentes de proposiçóes, a seleção das integrantes desses pares com o auxílio da referida forma ad hominem de argumentação indica que não há trivialização na presença de uma inconsistência. Aliás, uma importante passagem do Liber de syllogismis contradictoriis, onde o discípulo de Lúlio alerta seu contendor de que ambos não estão em contradição, mas em equivocação ${ }^{24}$ insinua, reforçada pela observaçáo presente no Liber contradictionis, segundo a qual num debate nem sempre os contendores se encontram propriamente em contradição, ${ }^{25}$ que Lúlio, assim como Síger, ${ }^{26}$ também evitaria a derivação de uma contradição a partir de uma inconsistência, interpretando as integrantes dos pares inconsistentes de proposiçôes como "é possível que $p$ " e "é possível que não- $p$ ". Verifica-se, portanto, que tal abordagem se distingue fundamentalmente pela adoção de uma postura adaptável em relação à ocorrência de inconsistências. De fato, após identificar uma inconsistência, a lógica subjacente ao método em questáo comporta-se em contextos inconsistentes de maneira paraconsistente, invalidando a aplicação de certas regras clássicas de inferência, embora também possa admitir em contextos consistentes o uso irrestrito de tais regras. ${ }^{27}$

\footnotetext{
${ }^{24}$ RAIMUNDO LÚLIO. Liber de syllogismis contradictoriis, p. 192: Auerroista, ait Raimundista, tu semper facis obiectiones cum tuo possibili, quod est inferius; et ego soluo tuas obiectiones cum possibili, quod est superius. Et ideo tu et ego sumus in aequiuocatione, non autem in contradictione'.

${ }^{25}$ Id. Liber contradictionis, p. 139: Dixit Contradictio: Mea essentia est in anima considerata, contracta et concepta. Habeo duas species, unam intensam per impossibile, aliam extensam per possibile. Per impossibile, quia circa idem non sum ens reale, ut puta: Per impossibile est, quod illud, quod est, non sit, dum est; et quod fuit, non fuerit; et quod album est, dum est album, sit nigrum, et e conuerso; et huiusmodi. Alia autem species est per possibile; et oritur a prima per accidens. Quae causat entia contraria, sicut est contrarietas inter calidum et frigidum, inter uerum et falsum, et huiusmodi. Ecce qualis sum. Aliqui autem credunt disputare per meam qualitatem intensam, et disputant per extensam, et e conuerso; et sic quid mirum, si non possunt conuenire. De fato, a distinção luliana entre contradição per impossibile e contradição per accidens aqui exposta é aparentemente análoga à distinção realizada por Aristóteles, na Metafísica, entre contradição e contrariedade (cf. JOHNSTON, M. The Spiritual Logic of Ramon Llull, p. 244). Sucintamente, Aristóteles esclarece que contradição e contrariedade sáo distintas, porque esta admite intermediários, ao passo que aquela não (Met. 1055a38-b5). Tais intermediários, contudo, pertencem ao mesmo gênero das coisas das quais são intermediários, na medida em que (i) são itens pelos quais deve passar qualquer coisa que se transforme em seu contrário e (ii) não é possível passar de um gênero para outro, a não ser per accidens (Met. 1057a18-29).

${ }^{26}$ Cf. p. 2-3.

${ }^{27}$ É particularmente notável a semelhança conceitual entre a lógica subjacente ao método dos silogismos contraditórios e a lógica discursiva $D_{2}^{r}$ da inconsistência adaptável, visto que, além de compartilharem o caráter paraconsistente e não permitirem a derivação de contradiçóes, ambas são efetivamente definidas em termos da lógica clássica (MEHEUS, J. An Adaptive Logic Based on Jaśkowski's Approach to Paraconsistency. Journal of Philosophical Logic, 35, p. 539-567, 2006. Sobre as lógicas da inconsistência
} 


\section{As SUPOSIÇÓES CONTRADITÓRIAS}

Poucos meses após expor a versão definitiva do método dos silogismos contraditórios, Lúlio redige seu Liber facilis scientiae, no qual declara ser capaz de combater aquelas proposiçóes filosóficas potencialmente desencadeadoras de divergências entre a razão e a fé católica, através de outra técnica argumentativa basicamente caracterizada como uma forma de reductio ad impossibile, que se vale de suposiçóes por ele chamadas de contraditórias. ${ }^{28}$ Mais eficiente do que o procedimento anterior, cuja capacidade probatória seria relativamente limitada, em função da dependência de um conjunto de premissas que encerraria apenas o que fora assumido pelo contendor envolvido, o novo método das suposiçóes contraditórias distingue-se simplesmente por derivar a oposta de qualquer suposição que acarrete uma impossibilidade. ${ }^{29}$

adaptável em geral, cf. BATENS, D. A Survey of Inconsistency-adaptive Logics. In: BATENS, D. et al. (Ed.). Frontiers of Paraconsistent Logic. Baldock, UK: Research Studies Press, 2000, p. 49-73).

${ }^{28}$ RAIMUNDO LÚLIO. Liber facilis scientiae, p. 304: Manifestum est, quod unum oppositorum cognoscitur per reliquum. Et ideo intendimus facere istum Librum siue Artem de suppositionibus contradictoriis, ut cognoscatur, quae propositio sit uera, et quae falsa. Et hoc intendimus exemplificare ad declarandam catholicam sanctam fidem contra aliquos philosophantes, dicentes, quod secundum modum intelligendi fides catholica est impossibilis. Embora se encontre plenamente desenvolvido, ao longo de 1311, não só no Liber facilis scientiae, mas também no Liber de efficiente et effectu, Liber de Deo ignoto et mundo ignoto e Liber de divina existentia et agentia, o método das suposições contraditórias fora originalmente empregado em 1310, tanto na oitava distinção do Liber de modo naturali intelligendi, quanto na segunda distinção do Liber in quo declaratur quod fides sancta catholica est magis probabilis. Cumpre ressaltar, porém, que, mesmo antes de elaborar o presente método, Lúlio já manifestara o interesse pelo aperfeiçoamento daquelas técnicas argumentativas por ele apresentadas em versôes anteriores de sua Arte, com o propósito de testar hipóteses ou suposiçôes. Realmente, em grande parte dos trabalhos redigidos ao final de 1308, tais como o Liber de novis fallaciis, o Liber de experientia realitatis Artis e o Liber de refugio intellectus, é possível observá-lo empregando outro método de argumentação que se vale de suposiçóes, a saber, a demonstratio per hypothesim.

${ }^{29}$ RAIMUNDO LÚLIO. Liber facilis scientiae, p. 304-5: Diuiditur iste liber in decem partes. Quae sunt hae: Diuina bonitas, magnitudo, aeternitas, potestas, intellectus, uoluntas, uirtus, ueritas, gloria et perfectio. Istae uero dignitates siue rationes praedicantur de Deo; et una similiter de alia praedicatur. Et hoc sic: Deus est bonitas, magnitudo, aeternitas etc; diuina bonitas est magnitudo, aeternitas etc,. et e conuerso, mutando subiectum in praedicatum. Et per talem praedicationem ueram et necessariam potest Deus definiri, et quaelibet eius ratio. Et hoc sic: Si quaeratur: Quid est Deus, respondeatur, quod Deus est bonitas, magnitudo etc; et si quaeratur: Quid est diuina bonitas, respondeatur, quod diuina bonitas est Deus et est magnitudo, aeternitas; et sic de aliis. De nullo uero ente alio tales definitiones esse possunt, cum istae sint supremae et in superlatiuo gradu permanentes. Ostenditur ergo, per quem modum potest Deus definiri et suae rationes, et per consequens faciliter cognosci. Applicatis ad propositum praedictis definitionibus cum suppositionibus contradictoriis faciliter potest cognosci, quae suppositio est uera, et quae falsa; quoniam illam suppositionem oportet esse ueram, primitiuam et necessariam, quae stat pro praedictis definitionibus; et sua contraria suppositio est falsa et impossibilis. Sobre outros métodos lulianos de argumentação que também recorrem aos vários tipos de reductio, cf. BONNER, A. The Art and Logic of Ramon Llull, p. 273-7. 
Em princípio, a passagem seguinte exemplifica o padrão dos argumentos propostos por Lúlio com base em tal método:

Suponho que seja bom, grande e verdadeiro que a bondade divina tenha tanto poder no tocante a si própria, quanto a eternidade divina no que diz respeito a si própria. E se a suposição contrária é boa, grande e verdadeira, segue-se necessariamente que é bom, grande e verdadeiro que o poder divino seja dividido: infinito quanto à eternidade em duração, mas finito no que concerne à bondade em bonificação. O que é falso e impossível, visto que as definiçōes preditas seriam violadas. Foi portanto demonstrado que a bondade divina é de tal forma infinita em vigor no que diz respeito à bonificação, como no que concerne à duraçấo. ${ }^{30}$

Ainda que o modo pelo qual Lúlio deriva uma impossibilidade a partir da suposição correspondente seja condicionado à existência de um antagonisno entre tal suposição e os princípios constitutivos da realidade ou dignidades divinas, ${ }^{31}$ a técnica argumentativa em questão revela seu caráter não construtivo, ao apoiar-se tanto no princípio que atesta ser falsa qualquer proposiçáo que acarrete uma falsidade, quanto no que afirma que duas proposiçóes opostas não podem ser simultaneamente falsas, para então determinar a verdade de

\footnotetext{
${ }^{30}$ RAIMUNDO LÚLIO. Liber facilis scientiae, p. 306-7: Suppono, quod sit bonum, magnum et uerum, quod diuina bonitas habeat tantam potestatem, quoad se ipsam, quantam diuina aeternitas quoad se ipsam. Et si contraria suppositio sit bona, magna et uera, necessarie sequitur, quod sit bonum, magnum et uerum, quod diuina potestas sit diuisa, infinita quoad aeternitatem in duratione, finita autem quoad bonitatem in bonificatione. Quod est falsum et impossibile, quoniam definitiones praedictae essent laesae. Demonstratum est ergo, quod diuina bonitas est ita infinita in uigore quoad bonificationem, sicut quoad durationem.

${ }^{31} \mathrm{O}$ início da passagem reproduzida na nota 28 esclarece como tais princípios interagem logicamente com determinada suposição, ao passo que o texto abaixo fixa as condiçóes epistemológicas dessa interação (RAIMUNDO LÚLIO. Liber de modo naturali intelligendi, p. 199: Decem et octo sunt principia uniuersalia totius uniuersi. Quae sunt haec: Bonitas, magnitudo, duratio, potestas, intellectus, uoluntas, uirtus, ueritas, gloria, differentia, concordantia, contrarietas, principium, medium, finis, maioritas, aequalitas et minoritas. Et quia intellectus coniunctus corpori constitutus est ex istis, naturam habet intelligendi cum istis, quoniam bonitate intelligit obiectum bonum, magnitudine uero obiectum magnum, duratione intelligit obiectum durabile; et sic de aliis. Quoniam intellectus cum omnibus principiis praedictis participat in natura, habet naturam miscendi unum principium cum alio, faciendo de quolibet subiectum respectu omnium aliorum et postea praedicatum. Et ideo ratione mixtionis considerat, quid sequitur, secundum quod per mixtionem significatur. Et tunc attingit naturaliter obiectum desideratum [...] Decem sunt modi faciendi quaestiones generaliter, uidelicet dicendo: Vtrum sit, quid sit, de quo est, quare est, quantum est, quale est, quando est, ubi est, quomodo est, et cum quo est res, de qua quaeritur. Quaelibet de istis quaestionibus generalibus habet suas species, ut patet in Arte generali. Et quia intellectus habet in potentia istos modos quaerendi, quando discurrit per ipsos uenando ueritatem, quod habet in potentia naturaliter, reducit ad actum, quaerendo et determinando [...] Intellectus considerans suam dispositionem et omnia, quae praedicta sunt, uenatur et determinat naturaliter affirmando uel negando. Et si quod quaerit cum principiis, est affirmatiuum, affirmat; si uero non, negat).
} 
uma das integrantes de um par incompatível de suposições, após a derivação da respectiva impossibilidade com base na suposição restante.

\section{CONSIDERAÇóEs FINAIS}

Sem dúvida, a análise das diferenças que caracterizam os métodos previamente avaliados esclarece até certo ponto a significativa evolução da postura de Lúlio em face dos eventuais conflitos entre a Filosofia e a Doutrina Cristã. Além da limitação que o uso exclusivo de premissas concedidas pelo respectivo contendor impóe à capacidade probatória do método dos silogismos contraditórios, uma modificação na forma de conceber as relaçóes entre fé e razão parece ter concorrido de maneira decisiva para que Lúlio desistisse de tal procedimento e passasse a desenvolver uma nova técnica argumentativa baseada na reductio ad impossibile. Realmente, há no prólogo de uma das obras que descrevem o método das suposiçóes contraditórias uma sugestiva passagem, onde Lúlio se aproxima da concepção de Tomás de Aquino, para quem, em última análise, os conflitos entre os artigos de fé e os primeiros princípios da Filosofia não seriam genuínos por compartilharem a mesma origem. ${ }^{32}$ Advertindo de início que "a Verdadeira Filosofia é serva da Verdadeira Teologia", ele acrescenta que

[...] o tema, porém, da teologia é Deus e o tema da filosofia é o inteligível. E porque o objeto do que entende é a verdade e Deus é a verdade, segue-se necessariamente que a verdadeira filosofia e a teologia concordam entre si. E por isso o oposto de tudo aquilo que é verdadeiramente inteligível não é verdadeiramente crível; de outro modo uma contradição seria implicada; mas uma contradição é impossível, ${ }^{33}$

\footnotetext{
${ }^{32}$ Cf. TOMÁS DE AQUINO. Expositio super librum Boethii De Trinitate, pars 1, q. 2, a. 3: [...] dona gratiarum hoc modo naturae adduntur quod eam non tollunt, sed magis perficiunt; unde et lumen fidei, quod nobis gratis infunditur, non destruit lumen naturalis rationis divinitus nobis inditum. Et quamvis lumen naturale mentis humanae sit insufficiens ad manifestationem eorum quae manifestantur per fidem, tamen impossibile est quod ea, quae per fidem traduntur nobis divinitus, sint contraria his quae sunt per naturam nobis indita. Oporteret enim alterum esse falsum; et cum utrumque sit nobis a deo, deus nobis esset auctor falsitatis, quod est impossibile; ID. Summa contra gentiles, lib. 1, cap. 7: Quamvis autem praedicta veritas fidei christianae humanae rationis capacitatem excedat, haec tamen quae ratio naturaliter indita habet, huic veritati contraria esse non possunt. Ea enim quae naturaliter rationi sunt insita, verissima esse constat: in tantum ut nec esse falsa sit possibile cogitare. Nec id quod fide tenetur, cum tam evidenter divinitus confirmatum sit, fas est credere esse falsum. Quia igitur solum falsum vero contrarium est, ut ex eorum definitionibus inspectis manifeste apparet, impossibile est illis principiis quae ratio naturaliter cognoscit, praedictam veritatem fidei contrariam esse.

${ }^{33}$ RAIMUNDO LÚLIO. Liber de efficiente et effectu, p. 274: [...] uera philosophia sit ancilla verae theologiae. Subiectum autem theologiae est Deus, et subiectum philosophiae est intelligibile. Et quia
} 
ratificando assim a legitimidade da aplicação da reductio ad impossibile no presente contexto e inviabilizando o recurso à interpretação modal das integrantes de um par inconsistente de proposiçôes com a finalidade de impedir a derivação de uma contradição, a partir de uma inconsistência.

WYLLIE, Guilherme. Suppositions and contradictory syllogisms as Lullian methods of inconsistency resolution. Trans/Form/Ação, Marília, v. 35, p. 209-224, 2012. Ediçấo Especial.

\begin{abstract}
In the early fourteenth century, Ramond Lully, opposed to university philosophers whom he identified as averroistae, developed no less than two methods for the resolution of inconsistency, in order to refute philosophical theses which diverge from the Christian faith. The first of these uses contradictory syllogisms expressing the structure of an ad hominem argument, while the other is a reductio ad impossibile produced with contradictory suppositions.
\end{abstract}

KEYWORDS: Contradictory Syllogisms. Contradictory Suppositions. Inconsistency Resolution Methods. Raymond Lully.

\title{
REFERÊNCIAS
}

ANÔNIMO. Quaestiones super primum librum Physicorum. In: ZIMMERMANN, A. (Ed.). Ein Kommentar zur Physik des Aristoteles aus der pariser Artistenfakultät um 1273. Berlin: Walter de Gruyter, 1968.

ARISTÓTELES. Topica et Sophistici elenchi (Ed. W. D. Ross) Oxford: Clarendon Press, 1958.

Press, 1924.

Metaphysics (Ed. W. D. Ross) Oxford: Clarendon Press, 1958. Oxford: Clarendon

BATENS, D. A Survey of Inconsistency-adaptive Logics. In: BATENS, D. et al. (Ed.). Frontiers of Paraconsistent Logic. Baldock, UK: Research Studies Press, 2000, p. 49-73.

BESNARD, P.; HUNTER, A. Elements of Argumentation. Cambridge, Mass.: MIT Press, 2008.

obiectum intelligentis est ueritas, et Deus est ueritas, necessarie sequitur, quod uera philosophia et theologia habeant concordantiam ad inuicem. Et ideo, quidquid est uere intelligibile, eius oppositum non est uere credibile; aliter implicaretur contradictio; sed contradictio est impossibilis. 
BOÉCIO DE DÁCIA. De aeternitate mundi. Trad. M. A. Santiago de Carvalho. Lisboa: Colibri, 1996.

BONNER, A. Syllogisms, Fallacies and Hypotheses: Llull's New Weapons to Combat the Parisian Averroists. In: DOMÍNGUEZ, F. et al. (Ed.) Aristotelica et lulliana. Steebrughe/La Haia: Abbadia Sancti Petri/MNI, 1995, Instrumenta patristica XXVI.

. The Art and Logic of Ramon Llull. A User's Guide. Leiden: Brill, 2007.

CHICHI, G. M. The Greek Roots of the ad hominem-Argument. Argumentation, 16, p. 333-348, 2002.

DE BONI, L. A. A entrada de Aristóteles no Ocidente Medieval. Porto Alegre: EST, 2010.

EBBESEN, S. The Paris arts faculty: Siger of Brabant, Boethius of Dacia, Radulphus Brito. In: MARENBON, J. (Ed.). Medieval Philosophy. Nova York: Routledge, 2003, p. 269-290.

IMBACH, R. Lulle face aux Averrö̈stes parisiens. In: Raymond Lulle et le Pays d'Oc. Toulouse: Édouard Privat, 1987, Cahiers de Fanjeaux 22.

JOHNSTON, M. The Spiritual Logic of Ramon Llull. Oxford: Clarendon Press, 1987.

KLIMA, G. Ancilla theologiae vs. domina philosophorum: St. Thomas Aquinas, Latin Averroism and the Autonomy of Philosophy. Disponível em: <http://www.fordham.edu/ gsas/phil/klima/ancilla. htm>. Acesso em: 07 jan. 2012.

MARENBON, J. Medieval Philosophy: An Historical and Philosophical Introduction. Nova York: Routledge, 2007.

MEHEUS, J. An Adaptive Logic Based on Jaśkowski’s Approach to Paraconsistency. Journal of Philosophical Logic, 35, p. 539-567, 2006.

NUCHELMANS, G. On the Fourfold Roots of the argumentum ad hominem. In: KRABE, E.C.W.; DALITZ, R.J.; SMIT, P. (Ed.). Empirical Logic and Public Debate. Amsterdam: Rodopi, 1993, p. 37-47.

PEDRO HISPANO. Tractatus called afterwards Summulae Logicales (Ed. L. M. De Rijk) Assen: Van Gorcum, 1972.

PUTALLAZ, F; IMBACH, R. Profession: Philosophe. Siger de Brabant. Paris: Les Éditions du Cerf, 1997.

RAIMUNDO LÚLIO. Liber contradictionis. (Ed. H. Harada) Turnhout: Brepols, 1975, ROL VII, p. 137-58.

Liber de syllogismis contradictoriis. (Ed. H. Harada) Turnhout: Brepols, 1975, ROL VII, p. 169-98. 303-17.

Liber facilis scientiae. (Ed. H. Harada) Turnhout: Brepols, 1975, ROL VII, p. Ars compendiosa Dei. (Ed. M. Bauzà) Turnhout: Brepols, 1985, ROL XIII, p. 15-331. 
Liber de modo naturali intelligendi. (Ed. H. Riedlinger) Turnhout: Brepols, 1978, ROL VI, p. 187-223.

SÍGER DE BRABANTE. Les Quaestiones super Librum de Causis de Siger de Brabant. (Ed. A. Marsala) Louvain: Publications Universitaires, 1972, Philosophes médiévaux XII.

De anima intellectiva. In: ID. Quaestiones in tertium de anima, de anima intellectiva, De aeternitate mundi. (Ed. B. C. Bazán) Louvain: Publications Universitaires, 1974, Philosophes médiévaux XIII.

. Quaestiones in Metaphysicam: Rep. Vienensis. (Ed. W. Dunphy) Louvain la Neuve: Éditions de l'Institut Supérieur de Phisosophie, 1981, Philosophes médiévaux XXIV.

TOMÁS DE AQUINO. In duodecim libros Metaphysicorum Aristotelis expositio (Ed. R. Spiazzi) Turin: Marietti, 1950. p. $401-418$.

De fallaciis. In: ID. Opera omnia. Roma: Editori di San Tommaso, 1976, XLIII, . Expositio super librum Boethii De Trinitate. (Ed. B. Decker) Leiden: Brill, 1965. . Summa contra gentiles. Taurini: Marietti, 1938.

VAN EEMEREN, F. H.; GROOTENDORST, R. The History of the argumentum ad hominem since the Seventeenth Century. In: KRABE, E.C.W.; DALITZ, R.J.; SMIT, P. (Ed.). Empirical Logic and Public Debate. Amsterdam: Rodopi, 1993, p. 49-68.

WIPPEL, J. Medieval Reactions to the Encounter Between Faith and Reason. Milwaukee: Marquettte University Press, 1995.

WYLLIE, G. Adaptive Reasoning in Ramon Llull's Liber de syllogismis contradictoriis. In: FIDORA, A.; SIERRA, C. (Org.). Ramon Llull: From Ars Magna to Artificial Intelligence. Menlo Park: AAAI Press, 2011, p. 117-123.

; FIDORA, A. Ramon Llull i el tractat De fallaciis del pseudo-Tomàs d'Aquino. Enrahonar, 42, p. 11-19, 2009. 
WYLLIE, G. 